Article

\title{
Construction Projects Assessment Based on the Sustainable Development Criteria by an Integrated Fuzzy AHP and Improved GRA Model
}

\author{
Seyed Morteza Hatefi ${ }^{1}$ (D) and Jolanta Tamošaitiene ${ }^{2, *(1)}$ \\ 1 Department of Civil Engineering, Faculty of Engineering, Shahrekord University, P.O. Box 115, \\ 64165478 Shahrekord, Iran, smhatefi@alumni.ut.ac.ir \\ 2 Civil Engineering Faculty, Vilnius Gediminas Technical University, Saulètekio al. 11, LT \\ 2040 Vilnius, Lithuania; jolanta.tamosaitiene@vgtu.lt \\ * Correspondence: jolanta.tamosaitiene@vgtu.lt
}

Received: 21 February 2018; Accepted: 23 March 2018; Published: 27 March 2018

check for updates

\begin{abstract}
Due to the increasing population and earth pollution, managing construction and infrastructure projects with less damage to the environment and less pollution is very important. Sustainable development aims at reducing damage to the environment, making projects economical, and increasing comfort and social justice. This study proposes fuzzy analytic hierarchy process (AHP) and improved grey relational analysis (GRA) to assess construction projects based on the sustainable development criteria. For doing so, sustainable development criteria are first identified in economic, social, and environmental dimensions using literature review, and are then customized for urban construction projects using experts' opinions. After designing questionnaires and collecting data, fuzzy AHP is used for determining the importance of sustainable development criteria and their subcriteria. Then, improved GRA is employed for assessing six recreational, commercial, and official centers in Isfahan regarding the weights of criteria and subcriteria. The proposed fuzzy AHP-improved GRA help us to prioritize construction projects based on the sustainable development criteria. The results of applying fuzzy AHP show that the weights of economic, social, and environmental criteria are equal to $0.330,0.321$, and 0.349 , respectively, which are close to each other. This means that the importance of all three aspects of sustainability is almost equal to each other. Furthermore, "Having profits for the society", "Increasing social justice", and "Adherence to environmental policies" are identified as the most important indicators of sustainable development in terms of economic, social, and environmental aspects, respectively. Finally, the results of employing improved GRA determine Negin Chaharbagh recreational and commercial complex as the best project.
\end{abstract}

Keywords: sustainability; project evaluation; construction projects; fuzzy theory; fuzzy multi-attribute decision-making methods

\section{Introduction}

The term "sustainable development" was first introduced in 1980 in the reports of International Union for Conservation of Nature (IUCN). This union used this term in a report named "the strategy for conservation of nature" to describe the condition that development can be useful for nature, not harmful. Sustainable development is, in fact, the balance between development and environment [1] with four aspects of sustainability in nature, politics, society, and economy. Not only does sustainable development focus on the environment, but it also pays attention to social and economical aspects. Sustainable development connects society, economy, and environment [2]. One important international 
event in this aspect is the international meeting for sustainable development in which participants agreed on points for sustainable development:

(1) Reducing, by half, the number of people who do not have access to water until 2015,

(2) Minimizing chemical materials harmful for human health and nature until 2000,

(3) Reducing, by half, the speed of decrease in maritime stores and bringing maritime resources to a sustainable level until 2015,

(4) Reducing the trend of nature destruction until 2010,

(5) Increasing sustainability in using renewable energy,

(6) Plans for preparing a ten year program about sustainable development.

The reasons behind the importance and the need for studying and reviewing sustainable development are air pollution (carbon dioxide and other gases) and its negative effects, greenhouse gases, ozone destruction, and acid rain, which result in incurable diseases [3]. From many decades ago, some documents read the need for economical and environmental policies at the global level, and predicted an increase in the above-mentioned problems. If there is an increase in population rate, air pollution, and fossil resources exploitation in industrial countries, these will cause a sudden and uncontrollable decrease in resources in the next years, and will change environmental and economical sustainability in a way that leads the international balance to severe shortages and the loss of opportunities for realizing human potentials [4,5]. Sustainability has penetrated many areas, especially the construction industry, due to its significant environmental impact. The green building is one of the most important issues of sustainable development. There are many definitions of green construction, in which the common elements of all definitions include the perspective of a life cycle, sustainable environment, health issues, and its effects on society. In simple terms, green building can be considered as building on the basis of environmental considerations, which seeks to reduce pollution during construction, operation, and destruction, such as noise pollution, water, dust, and greenhouse gases, as well as the use of renewable energy and minimizing non-renewable energy. Therefore, sustainability in the construction industry has important implications for economic and environmental sustainability. With the rapid growth of this industry in the coming years, and the need for materials as well as waste generation, the use of sustainable materials and technologies in this industry will be a major contributor to sustainable development. Regarding these issues, the evaluation of construction projects based on the dimensions of sustainable development is very essential [6]. In an article named "designing sustainable construction", it is stated that extensive and multi-fields efforts in mechanics, electronic and electrical devices, communication, acoustics, architecture, and structural engineering are made all over the world for designing sustainable constructions. This is cooperation among owners, suppliers, contractors, and users, and extensive studies have been done on sustainable constructions since many years ago. The results show that saving energy and water and making constructions compatible with the environment significantly prevents carbon dioxide emission in the atmosphere. This study presents strategies for designing sustainable constructions, using the integration of smart structure technology and a combination of semi-active vibration control that lead into lighter and more efficient constructions [6]. In one study, authors identified key criteria of construction, and using fuzzy analytic hierarchy process assessed smart constructions. This study introduced key criteria related to smart sustainable constructions in the domains of environment, society, economy, and technical factors. Then, based on the group analytic hierarchy process, assessed the sustainability of smart constructions [7]. In one study, global warming was referred to as a big challenge for human survival. Carbon dioxide density increase helps global warming. Due to increase in constructions and change in climate, end to fossil fuels, restriction in area and resources, geothermal energy can be used for sustainable development. This study presents methods for employing such energy in infrastructure construction, based on the history and classification of criteria of thermal energy performance which is presented in the form of different designs, applications, setting, and climate table [8]. There are different studies on assessing 
construction projects in the literature review. Mousavi et al. [9] used a model based on fuzzy logic and fuzzy TOPSIS for determining the performance of construction projects. Functional criteria for assessing projects in this study are operational criteria, financial criteria, technological criteria, and criteria related to state requirements. In another study, Vahdani et al. [10] presented a hybrid model based on support vector machine for assessing and selecting the best construction project. The study utilized technological criteria, budget amount, state requirements, and resource restrictions for determining the performance of construction projects. Some other studies utilized risk factors for assessing construction projects [11,12]. Tailan et al. [13] utilized five risk criteria and evaluated 30 construction projects based on fuzzy analytic hierarchy process model and fuzzy TOPSIS model. Time risk, expense risk, quality risk, and risk related to environmental sustainability were utilized for assessing construction projects. Islam et al. [14] used risk factors to assess construction projects based on fuzzy multi-criteria decision-making methods. One recent study has assessed a tunneling project based on five risk factors namely time risk, expense risk, quality risk, safety risk, and environment sustainability risk $[15,16]$. According to the literature review, most studies utilize risk factors for assessing construction projects, while this study uses sustainable development criteria for construction projects evaluation. Regarding the method of construction in our country and utilizing modern construction materials, this industry suffers from different problems among which inadequate resistance against earthquake, short life of the building, erosion due to climate, excessive waste construction while execution, inefficiency of recycling construction materials, and etc., and utilizing unskilled labor force result in unendurable buildings and structures. Moreover, no attention is paid to environment in the domains of destruction, co-existence, and utilization of recycled materials. Due to the importance of this issue, construction projects are assessed via fuzzy analytic hierarchy process and improved grey relational analysis based [17] on sustainable development criteria.

\section{The Proposed Model}

This study utilized fuzzy analytic hierarchy process and improved grey relational analysis for assessing six commercial, tourism, and recreational projects in Isfahan megacity. Isfahan is a historical city at the center of Iran. Its center is Isfahan and is the 3rd most-populated city after Tehran and Mashhad, and known as "Nesfe Jahan" in Iranian culture. It is famous for its Islamic architecture and beautiful boulevards, covered bridges, beautiful tunnels, palaces, mosques, and unique minarets (Figure 1).

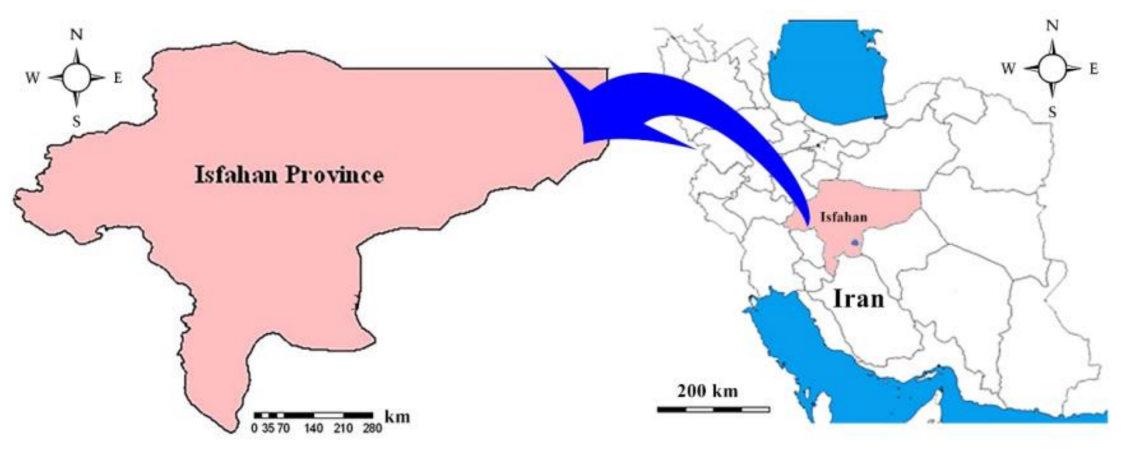

Figure 1. The study area.

The proposed model of fuzzy AHP and improved GRA for assessing construction projects in Isfahan megacity include the steps shown graphically in Figure 2. In the proposed model, criteria of sustainable development are identified in three aspects of economy, society, and environment using literature and experts' ideas. Then two questionnaires related to fuzzy AHP and improved GRA were designed. After distributing the questionnaires and collecting experts' ideas, fuzzy AHP was 
used for determining the weights of sustainable development criteria, and finally, improved GRA is applied for determining the final weights and ranks of construction projects in Isfahan megacity.

\subsection{Fuzzy AHP}

Fuzzy AHP, which was first introduced by Tomas Saaty in 1980 [18], is one of the most comprehensive systems for multi-criteria decision-making. This technique makes possible formulating the problem hierarchically, and can consider different quantity and quality criteria in the problem. This process integrates different options in decision-making and can analyze the sensitivity of criteria and subcriteria. Pairwise comparisons facilitate judgements and computations. It shows the compatibility and incompatibility of the decisions which is a benefit of multi-criteria decision-making. It contains a strong theoretical basis and is based on axiomatic principles [19]. Although experts utilize their abilities and aptitude for doing comparisons in AHP, we should consider that traditional AHP cannot completely reflect human thoughts. Fuzzy numbers are more compatible with phrases and ambiguities, so, it is better to utilize them in decisions in the real world. The following part shows the steps of implementing fuzzy AHP introduced by Chang [20].

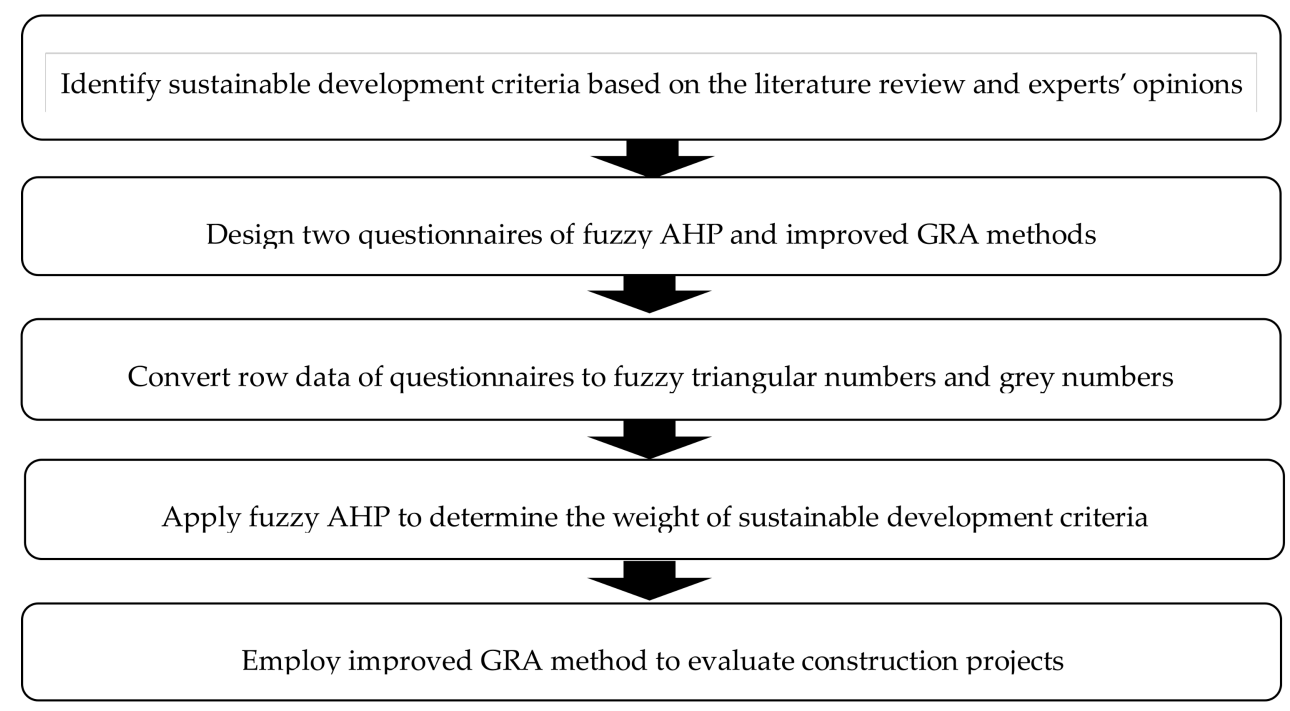

Figure 2. The proposed model.

\subsubsection{Defining Relevant FUZZY Numbers for Determining the Importance of Criteria}

At first, the convenient fuzzy numbers were defined for doing pairwise comparisons. Table 1 is used for preprocessing data and converting row data of questionnaires to corresponding fuzzy numbers.

Table 1. Linguistic terms and the corresponding triangular fuzzy numbers [21].

\begin{tabular}{ccc}
\hline Linguistic Term & Fuzzy Number & Reverse Fuzzy Number \\
\hline Equally Preferred & $(1,1,1)$ & $(1,1,1)$ \\
Moderately Preferred & $(2,3,4)$ & $\left(\frac{1}{4}, \frac{1}{3}, \frac{1}{2}\right)$ \\
Strongly Preferred & $(4,5,6)$ & $\left(\frac{1}{6}, \frac{1}{5}, \frac{1}{4}\right)$ \\
Very Strongly Preferred & $(6,7,8)$ & $\left(\frac{1}{8}, \frac{1}{7}, \frac{1}{6}\right)$ \\
Extremely Preferred & $(9,9,9)$ & $\left(\frac{1}{9}, \frac{1}{9}, \frac{1}{9}\right)$ \\
\hline
\end{tabular}




\subsubsection{Forming Fuzzy Pairwise Comparison Matrix}

In this stage, the matrix for fuzzy pairwise comparison matrix is provided. If there is more than one expert, geometric average is used for aggregating experts' opinions. In this stage, the aggregated fuzzy decision matrix is constructed based on the geometric average of fuzzy decision matrixes obtained by all experts.

\subsubsection{Calculating the Relative Weight for Each Row of Fuzzy Pairwise Comparison Matrix $\left(\widetilde{S}_{i}\right)$}

If fuzzy numbers are triangular, they are shown as $\left(l_{i}, m_{i}, u_{i}\right)$, then $\widetilde{S}_{i}$ is calculated in the following way.

$$
\begin{gathered}
\widetilde{S}_{i}=\sum_{j=1}^{m} M_{g i}^{j} \times\left[\sum_{i=1}^{n} \sum_{j=1}^{m} M_{g i}^{j}\right]^{-1} \\
\sum_{j=1}^{m} M_{g i}^{j}=\left(\sum_{j=1}^{m} l_{j}, \sum_{j=1}^{m} m_{j}, \sum_{j=1}^{m} u_{j}\right) \\
\sum_{i=1}^{n} \sum_{j=1}^{m} M_{g i}^{j}=\left(\sum_{i=1}^{n} l_{i}, \sum_{i=1}^{n} m_{i}, \sum_{i=1}^{n} u_{i}\right) \\
{\left[\sum_{i=1}^{n} \sum_{j=1}^{m} M_{g i}^{j}\right]^{-1}=\left(\frac{1}{\sum_{i=1}^{n} u_{i}}, \frac{1}{\sum_{i=1}^{n} m_{i}}, \frac{1}{\sum_{i=1}^{n} l_{i}}\right)}
\end{gathered}
$$

2.1.4. Calculating the Bigness Degree of $\widetilde{S}_{i}$

If $\widetilde{M}_{1}=\left(l_{1}, m_{1}, u_{1}\right)$ and $\tilde{M}_{2}=\left(l_{2}, m_{2}, u_{2}\right)$ are two triangular fuzzy numbers, then the degree of possibility of $\widetilde{M}_{2} \geq \widetilde{M}_{1}$ is calculated as

$$
V\left(M_{2}>M_{1}\right)=\operatorname{hgr}\left(M_{2}>M_{1}\right)=\mu_{M_{2}}(d)=\left\{\begin{array}{cc}
1 & \text { if } m_{2} \geq m_{1} \\
0 & \text { if } l_{1} \geq u_{2} \\
\frac{l_{1}-u_{2}}{\left(m_{2}-u_{2}\right)-\left(m_{1}-l_{1}\right)} & \text { otherwise }
\end{array}\right.
$$

\subsubsection{Calculating the Weights by the Possibility Degree}

Possibility degree of a convex fuzzy number is more than that of $k$ convex fuzzy numbers can be calculated according to the following formulation. This concept can be stated in the following way.

$$
\begin{aligned}
V\left(\widetilde{M}>\widetilde{M}_{1}, \widetilde{M}_{2}, \ldots . ., \widetilde{M}_{k}\right) & =V\left(\widetilde{M}>\widetilde{M}_{1}\right) \text { and } V\left(\widetilde{M}>\widetilde{M}_{2}\right) \ldots . \text { and } V\left(\widetilde{M}>\widetilde{M}_{k}\right) \\
& =\min V\left(\widetilde{M}>\widetilde{M}_{k}\right), i=1,2, \ldots, k
\end{aligned}
$$

Based on the above concept, the weight vector is calculated as follows:

$$
\begin{aligned}
& d_{i}^{\prime}\left(A_{i}\right)=\min V\left(S_{i}>S_{k}\right), k=1,2, \ldots ., n, k \neq i \\
& W^{\prime}=\left(d^{\prime}\left(A_{1}\right), d^{\prime}\left(A_{2}\right), \ldots, d^{\prime}\left(A_{n}\right)\right)^{T}
\end{aligned}
$$

\subsubsection{Normalizing the Weight Vector}

After normalizing $W^{\prime}$ vector, the normalized weight vector $(W)$ whose elements are non-fuzzy numbers is defined as

$$
W=\left(d\left(A_{1}\right), d\left(A_{2}\right), \ldots ., d\left(A_{n}\right)\right)^{T}
$$




\subsection{Improved Grey Relational Analysis}

Deng [22-24] presented the first article on grey system theory named controlling grey systems, and then introduced grey system theory. Generally, its idea is that by concentrating on minor or restricted details about a decision, a general picture of it will be imagined. So, this method deals with defective, weak, and uncertain issues. This method can have satisfactory results with a little information and a lot of change in criteria. Grey theory refers to an effective mathematical model for solving uncertain and vague problems by combining with a MCDM method $[25,26]$. When the units are assessed by different criteria, the effects of some will be ignored. This happens especially when performance criteria are large in their amount, and when the aims and instructions of these criteria are different; then the results of analysis will be incorrect. Suppose that $\otimes G=[\underline{G}, \bar{G}]$ is a grey number, with $\underline{G}$ as the lower bound and $\bar{G}$ as the upper bound of the grey number. Furthermore, suppose that we have a decision-making matrix with all its entries as grey numbers with $m$ units of decisions (alternatives) and $n$ criteria shown in the following way:

$$
\otimes G=\left[\begin{array}{cccc}
\otimes G_{11} & \otimes G_{12} & \cdots & \otimes G_{1 n} \\
\otimes G_{21} & \otimes G_{22} & \cdots & \otimes G_{2 n} \\
\vdots & \vdots & \ddots & \vdots \\
\otimes G_{m 1} & \otimes G_{m 2} & \cdots & \otimes G_{m n}
\end{array}\right]
$$

In the above matrix, $\otimes G_{i j}$ is the $j$-th criterion for the $i$-th choice. The algorithm of improved grey relational analysis is introduced by Hashemi et al. [17], and has the following steps.

\subsubsection{Preparing a Decision Matrix and Normalized Decision Matrix}

Interval grey numbers are used for assessing alternatives based on criteria. For doing so, a questionnaire is designed and sent to respondents. Then, after gathering row data of questionnaires, they are converted to the corresponding interval grey numbers according to Table 2.

Table 2. Linguistic terms and correspondent interval grey numbers.

\begin{tabular}{cccccc}
\hline & Very Low & Low & Medium & High & High \\
\hline$\otimes G$ & {$[0,1]$} & {$[1,4]$} & {$[4,6]$} & {$[6,9]$} & {$[9,10]$} \\
\hline
\end{tabular}

After preparing the decision matrix, a normalized decision matrix is prepared based on the following relations.

$$
\begin{aligned}
& \otimes y_{i j}=\frac{\otimes G_{i j}}{\operatorname{Max}\left\{\bar{G}_{i j}, i=1,2, \ldots, m\right\}} \text { for } i=1,2, \ldots, m, j=1,2, \ldots, n \\
& \otimes y_{i j}=\frac{\operatorname{Min}\left\{\underline{G}_{i j}, i=1,2, \ldots, m\right\}}{\otimes G_{i j}} \text { for } i=1,2, \ldots, m, j=1,2, \ldots, n
\end{aligned}
$$

Relation (10) is used for benefit criteria, and Relation (11) is used for cost criteria. The benefit and cost criteria are identified based on the experts' ideas and the literature review.

\subsubsection{Defining Reference Alternative}

Reference alternative are taken from normalized decision matrix according to the following equation:

$$
\begin{aligned}
& y^{0}=\left\{y_{1}^{0}, y_{2}^{0}, \ldots . ., y_{n}^{0}\right\} \\
& \otimes y_{j}^{0}=\left(\max _{i=1}^{m} \underline{y}_{i j^{\prime}} \max _{i=1}^{m} \bar{y}_{i j}\right) \text { for } j=1,2, \ldots ., n
\end{aligned}
$$


In the above relation, $y_{j}^{0}$ is the reference amount for the $j$-th criterion and $y_{i j}$ are the entries of the normalized matrix.

\subsubsection{Calculating the Difference between Alternatives and Reference Alternative}

In this stage, the difference between each alternative and reference alternative is obtained, and then the difference matrix is constructed as follows:

$$
\begin{aligned}
& \otimes \Delta=\left[\begin{array}{cccc}
\otimes \Delta_{11} & \otimes \Delta_{12} & \cdots & \otimes \Delta_{1 n} \\
\otimes \Delta_{21} & \otimes \Delta_{22} & \cdots & \otimes \Delta_{2 n} \\
\vdots & \vdots & \ddots & \vdots \\
\otimes \Delta_{m 1} & \otimes \Delta_{m 2} & \cdots & \otimes \Delta_{m n}
\end{array}\right] \\
& \otimes \Delta_{i j}=\left[y_{j}^{0}-\bar{y}_{i j}, y_{j}^{0}-\underline{y}_{i j}\right] \text { for } i=1, \ldots, m ; j=1, \ldots, m
\end{aligned}
$$

\subsubsection{Calculating Grey Relational Coefficient}

Grey relational coefficient is defined for determining how to make the alternatives closer to the reference alternative. Equation (14) is utilized for calculating grey relational coefficient.

$$
\begin{aligned}
& \otimes \gamma_{i j}=\left[\underline{\gamma}_{i j^{\prime}} \bar{\gamma}_{i j}\right] \\
& \underline{\gamma}_{i j}=\frac{\min _{i=1}^{m} \min _{j=1}^{n} \underline{\Delta}_{i j}+\rho \max _{i=1}^{m} \max _{j=1}^{n} \bar{\Delta}_{i j}}{\bar{\Delta}_{i j}+\rho \max _{i=1}^{m} \max _{j=1}^{n} \bar{\Delta}_{i j}} \\
& \bar{\gamma}_{i j}=\frac{\min _{i=1}^{m} \min _{j=1}^{n} \underline{\Delta}_{i j}+\rho \max _{i=1}^{m} \max _{j=1}^{n} \bar{\Delta}_{i j}}{\underline{\Delta}_{i j}+\rho \max _{i=1}^{m} \max _{j=1}^{n} \bar{\Delta}_{i j}}
\end{aligned}
$$

where $\otimes \gamma_{i j}$ is grey relational coefficient $\rho$ is distinguishing coefficient, taking the value of 0.5 in this study.

\subsubsection{Calculating Grey Relational Degree for Each Alternative}

After calculating grey relational coefficient, grey relational degree for each alternative is calculated in the following way:

$$
\otimes \Gamma_{i}=\left[\underline{\Gamma}_{i}, \bar{\Gamma}_{i}\right]=\left[\sum_{j=1}^{n} \underline{\gamma}_{i j} \cdot w_{j}, \sum_{j=1}^{n} \bar{\gamma}_{i j} \cdot w_{j}\right] \text { for } i=1,2, \ldots, m
$$

\subsubsection{Whitening the Grey Relational Degree for Each Alternative}

The grey relational degrees for each alternative can be whitened by using Equation (16). The alternatives are prioritized based on the rule that the bigger the whitened relational degree, the better the corresponding alternative.

$$
\Gamma_{i}=\frac{\Gamma_{i}+\bar{\Gamma}_{i}}{2}
$$

\section{Results and Discussion}

\subsection{Case Study}

Fuzzy AHP and improved GRA are applied to assess six recreational, tourism, and commercial projects in Isfahan megacity based on the dimensions of sustainable development. In this research, only the investment projects that are under construction or ready for exploitation are considered. These projects are diverse, and just recreational and tourism projects are considered. These projects form decision alternatives and are Fadak center recreational, tourism, and commercial complex $\left(\mathrm{P}_{1}\right)$, 
Anoshirvan recreational, commercial, and official complex $\left(\mathrm{P}_{2}\right)$, Goldasteh garden recreational, service, and commercial complex $\left(\mathrm{P}_{3}\right)$, Negin Chaharbagh recreational and commercial complex $\left(\mathrm{P}_{4}\right)$, Sepahan recreational and commercial complex $\left(\mathrm{P}_{5}\right)$, and ShahrRoyaha recreational and commercial complex $\left(\mathrm{P}_{6}\right)$. Criteria of sustainable development in three aspects of economy, society, and environment should be first identified for assessing the above projects. Table 3 shows criteria of sustainable development, which are extracted from literature review and experts' opinions.

Table 3. Criteria and subcriteria of sustainable development in construction projects.

\begin{tabular}{|c|c|c|}
\hline Main Criteria & Subcriteria & Notation \\
\hline \multirow{8}{*}{ Economical $\left(\mathrm{C}_{1}\right)$} & Technology promotion after project completion & $\mathrm{C}_{11}$ \\
\hline & Absorbing foreign capital & $\mathrm{C}_{12}$ \\
\hline & Paying attention to society and market needs & $\mathrm{C}_{13}$ \\
\hline & Having profits for the society & $\mathrm{C}_{14}$ \\
\hline & Cost effectiveness/Economic profit & $\mathrm{C}_{15}$ \\
\hline & Positive impact on the region's economy & $\mathrm{C}_{16}$ \\
\hline & Information on risks and financial risks & $\mathrm{C}_{17}$ \\
\hline & $\begin{array}{l}\text { Construction and architecture requirement for } \\
\text { making the projects economical }\end{array}$ & $\mathrm{C}_{18}$ \\
\hline \multirow{8}{*}{ Social $\left(C_{2}\right)$} & Welfare and economical growth & $\mathrm{C}_{21}$ \\
\hline & Society development and renovation & $\mathrm{C}_{22}$ \\
\hline & Creating equal job opportunities & $C_{23}$ \\
\hline & Paying attention to cultural heritage & $\mathrm{C}_{24}$ \\
\hline & Paying attention to the beauty and customs of the area & $\mathrm{C}_{25}$ \\
\hline & Public participation and project control & $\mathrm{C}_{26}$ \\
\hline & No risk to people in the region & $\mathrm{C}_{27}$ \\
\hline & Increasing social justice & $\mathrm{C}_{28}$ \\
\hline \multirow{10}{*}{ Environmental $\left(\mathrm{C}_{3}\right)$} & Use of eco-friendly technologies & $\mathrm{C}_{31}$ \\
\hline & Waste management system & $\mathrm{C}_{32}$ \\
\hline & Energy efficient management & $\mathrm{C}_{33}$ \\
\hline & No greenhouse gas emissions & $\mathrm{C}_{34}$ \\
\hline & Protection of plants and animals & $\mathrm{C}_{35}$ \\
\hline & Optical and visual non-pollution & $\mathrm{C}_{36}$ \\
\hline & Preventing nature destruction & $\mathrm{C}_{37}$ \\
\hline & Using thermal, wind, and sun energy & $\mathrm{C}_{38}$ \\
\hline & Non-pollution of surface water and underground water & $\mathrm{C}_{39}$ \\
\hline & Adherence to environmental policies & $\mathrm{C}_{310}$ \\
\hline
\end{tabular}

This study collects the intended information based on library research, questionnaire, field research, and experts' ideas. The statistical population is a set of units that are common in one or more than one attribute. It is obvious that we should take into account the judgements of experts and theorists in the domain of project management, civil engineering (construction management, civil, metro), architecture (sustainable architecture), and urban management and planning, to have an exact and comprehensive response. An attempt is made to identify these experts and connect to them. For this purpose, 20 experts were identified to complete the questionnaires. These experts had enough information about the construction projects being investigated, and met one of the following requirements: having at least one professional degree in project management, having significant compilations in one domain of sustainable development and project management, postgraduate students at industrial engineering, project management, or one of the fields of engineering, and having professional resume in researching and running and managing infrastructure projects. The study reached the following results by extracting data from questionnaires and analyzing them using fuzzy AHP and improved GRA. 


\subsection{The Results of Applying Fuzzy AHP}

Computational results of fuzzy AHP method are as follows:

- Pairwise comparison of main criteria with respect to goal and determining the local weights of main criteria.

- Pairwise comparison of subcriteria with respect to their criteria and determining the local weights of subcriteria.

- Multiplying the local weights of subcriteria to the local weight of the related criterion for determining the final weight of subcriteria

The fuzzy rating reported in Table 1 was used to obtain pairwise comparisons and construct pairwise comparison matrix. Aggregated fuzzy pairwise matrix is calculated based on the geometric mean of the ideas of 20 experts for the main criteria of sustainable development, and is reported in Table 4. For calculating local weights related to main criteria of sustainable development, Equations (1)-(8) should be applied on integrated fuzzy pairwise comparison matrix. For example, fuzzy expansion $\widetilde{S}_{i}$ is calculated for each main criterion. According to Equations (1)-(4), fuzzy expansion of each main criterion is calculated in the following way:

$$
\begin{aligned}
& {\left[\sum_{i=1}^{n} \sum_{j=1}^{m} M_{g i}^{j}\right]^{-1}=(0.081,0.092,0.104)} \\
& \widetilde{S}\left(C_{1}\right)=(3.400,3.630,3.890) \times(0.081,0.092,0.104)=(0.277,0.333,0.403) \\
& \widetilde{S}\left(C_{2}\right)=(3.040,3.560,4.130) \times(0.081,0.092,0.104)=(0.248,0.326,0.428) \\
& \widetilde{S}\left(C_{3}\right)=(3.210,3.720,4.250) \times(0.081,0.092,0.104)=(0.262,0.341,0.440)
\end{aligned}
$$

Table 4. Pairwise comparison matrix of main criteria.

\begin{tabular}{cccc}
\hline & Economical Criterion $\left(\mathbf{C}_{\mathbf{1}}\right)$ & Social Criterion $\left(\mathbf{C}_{2}\right)$ & Environmental Criterion $\left(\mathbf{C}_{3}\right)$ \\
\hline Economical criterion $\left(C_{1}\right)$ & $(1,1,1)$ & $(0.39,0.48,0.61)$ & $(0.33,0.39,0.47)$ \\
Social criterion $\left(C_{2}\right)$ & $(1.64,2.08,2.54)$ & $(1,1,1)$ & $(0.40,0.48,0.59)$ \\
Environmental criterion $\left(C_{3}\right)$ & $(2.14,2.56,3.03)$ & $(1.69,2.08,2.48)$ & $(1,1,1)$ \\
\hline
\end{tabular}

After calculating $\widetilde{S}_{i}$ for main criteria, the bigness degree of $\widetilde{S}_{i}$ is calculated based on Equation (5) for main criteria. The results are reported in Table 5, in which element of row $i$ and column $j$ shows $V\left(S_{i}>S_{j}\right)$. Finally, the non-normalized and normalized weights of main criteria can be extracted from Equations (6)-(8). The normalized and non-normalized weights of the main criteria are as follows:

$$
\begin{aligned}
& W^{\prime}=(0.945,0.919,1.000)^{T} \\
& W=(0.330,0.321,0.349)^{T}
\end{aligned}
$$

Table 5. The bigness degree of $\widetilde{S}_{i}$ in relation to other criteria $V\left(S_{i}>S_{j}\right)$.

\begin{tabular}{cccc}
\hline & $j=\mathbf{1}$ & $\boldsymbol{j}=\mathbf{2}$ & $\boldsymbol{j}=\mathbf{3}$ \\
\hline$i=1$ & 1 & 1 & 0.945 \\
$i=2$ & 0.959 & 1 & 0.919 \\
$i=3$ & 1 & 1 & 1 \\
\hline
\end{tabular}

As the results show, environmental dimension with the weight of 0.349 has the most importance among the sustainable development dimensions in construction projects in Isfahan. The second and the third ranks belong to economic and social themes, respectively. Similarly, local weights of 
subcriteria of sustainable development can be calculated. Table 6 shows the local weights of sustainable development criteria, local weights of subcriteria, and the final weights of subcriteria. It should be mentioned that final weights of each subcriterion are obtained by multiplying the local weight of the respective main criterion to the local weight of that subcriterion. Based on the results reported in Table 6 , it can be concluded that among subcriteria of sustainable development in construction projects, "adherence to environmental policies" $\left(\mathrm{C}_{310}\right)$, "having profits for the society" $\left(\mathrm{C}_{14}\right)$, and "paying attention to society and market needs" $\left(\mathrm{C}_{13}\right)$ are the most important subcriteria.

Table 6. The weights of criteria and subcriteria of sustainable development in infrastructure projects.

\begin{tabular}{ccccc}
\hline Main Criteria & Local Weight & Subcriteria & Local Weight & Final Weight \\
\hline & & $\mathrm{C}_{11}$ & 0.065 & 0.021 \\
& $\mathrm{C}_{12}$ & 0.057 & 0.019 \\
& & $\mathrm{C}_{13}$ & 0.172 & 0.057 \\
$\mathrm{C}_{1}$ & $\mathrm{C}_{14}$ & 0.174 & 0.057 \\
& \multirow{3}{*}{0.330} & $\mathrm{C}_{15}$ & 0.126 & 0.042 \\
& & $\mathrm{C}_{16}$ & 0.147 & 0.049 \\
& & $\mathrm{C}_{17}$ & 0.131 & 0.043 \\
& $\mathrm{C}_{18}$ & 0.129 & 0.043 \\
\hline & $\mathrm{C}_{21}$ & 0.114 & 0.037 \\
& & $\mathrm{C}^{22}$ & 0.105 & 0.034 \\
& & $\mathrm{C}_{23}$ & 0.091 & 0.029 \\
$\mathrm{C}_{2}$ & $\mathrm{C}_{24}$ & 0.131 & 0.042 \\
& & $\mathrm{C}_{25}$ & 0.089 & 0.029 \\
& & $\mathrm{C}_{26}$ & 0.095 & 0.030 \\
& & $\mathrm{C}_{27}$ & 0.111 & 0.036 \\
& & $\mathrm{C}_{28}$ & 0.164 & 0.053 \\
\hline & $\mathrm{C}_{31}$ & 0.093 & 0.032 \\
& & $\mathrm{C}_{32}$ & 0.057 & 0.020 \\
& & $\mathrm{C}_{33}$ & 0.070 & 0.024 \\
$\mathrm{C}_{3}$ & & $\mathrm{C}_{34}$ & 0.089 & 0.031 \\
& & $\mathrm{C}_{35}$ & 0.095 & 0.033 \\
& & $\mathrm{C}_{36}$ & 0.133 & 0.046 \\
& & $\mathrm{C}_{37}$ & 0.093 & 0.032 \\
& & $\mathrm{C}_{38}$ & 0.107 & 0.037 \\
& & $\mathrm{C}_{39}$ & 0.118 & 0.041 \\
& & $\mathrm{C}_{310}$ & 0.166 & 0.058 \\
\hline
\end{tabular}

\subsection{The Results of Applying Improved GRA}

For implementing the improved GRA, the ideas of 20 experts about assessing alternatives with respect to subcriteria will be collected based on a questionnaire. To do this, experts state their ideas about satisfying each subcriterion in each alternative based on linguistic terms reported in Table 2 . After collecting the row data in the form of linguistic terms, they are converted to grey numbers according to Table 2 . Then, the grey relational decision matrix is obtained based on the arithmetic mean of grey numbers taken from 20 experts' opinions. Table 7 shows grey decision matrix in which elements are in the form of interval grey numbers, and present the scores of alternatives with respect to subcriteria. 
Table 7. Grey relational decision matrix.

\begin{tabular}{|c|c|c|c|c|c|c|}
\hline & $\mathbf{P}_{1}$ & $\mathbf{P}_{2}$ & $\mathbf{P}_{3}$ & $\mathbf{P}_{4}$ & $\mathbf{P}_{5}$ & $\mathbf{P}_{6}$ \\
\hline $\mathrm{C}_{11}$ & {$[5.35,7.35]$} & {$[4.88,6.88]$} & {$[5.61,6.78]$} & {$[5.77,7.19]$} & {$[3.94,5.17]$} & {$[4.23,5.28]$} \\
\hline $\mathrm{C}_{12}$ & {$[3.24,5.24]$} & {$[4.97,6.55]$} & {$[1.64,2.75]$} & {$[6.01,7.60]$} & {$[6.41,7.94]$} & {$[4.79,6.18]$} \\
\hline $\mathrm{C}_{13}$ & {$[3.69,5.18]$} & {$[5.41,7.02]$} & {$[3.79,5.04]$} & {$[6.02,7.41]$} & {$[1.19,2.83]$} & {$[3.76,5.19]$} \\
\hline $\mathrm{C}_{14}$ & {$[5.66,6.67]$} & {$[5.52,6.58]$} & {$[5.06,6.13]$} & {$[6.54,8.43]$} & {$[5.75,6.96]$} & {$[4.38,5.93]$} \\
\hline $\mathrm{C}_{15}$ & {$[1.76,3.21]$} & {$[5.03,6.36]$} & {$[5.06,6.14]$} & {$[6.39,7.46]$} & {$[1.96,3.50]$} & {$[4.15,6.08]$} \\
\hline $\mathrm{C}_{16}$ & {$[4.76,6.17]$} & {$[5.84,6.84]$} & {$[4.79,6.60]$} & {$[5.56,7.41]$} & {$[1.70,3.06]$} & {$[4.51,6.34]$} \\
\hline $\mathrm{C}_{17}$ & {$[2.65,4.01]$} & {$[4.78,6.67]$} & {$[5.09,6.91]$} & {$[6.94,7.97]$} & {$[5.21,6.59]$} & {$[3.85,5.64]$} \\
\hline $\mathrm{C}_{18}$ & {$[1.16,2.53]$} & {$[5.94,7.38]$} & {$[1.69,3.21]$} & {$[6.52,8.05]$} & {$[6.30,7.37]$} & {$[5.18,6.32]$} \\
\hline $\mathrm{C}_{21}$ & {$[2.73,4.22]$} & {$[6.20,7.38]$} & {$[6.26,7.61]$} & {$[6.80,8.16]$} & {$[1.71,2.92]$} & {$[5.13,6.16]$} \\
\hline $\mathrm{C}_{22}$ & {$[5.62,6.64]$} & {$[5.37,7.11]$} & {$[1.11,2.41]$} & {$[5.35,7.33]$} & {$[1.27,2.87]$} & {$[4.12,5.67]$} \\
\hline $\mathrm{C}_{23}$ & {$[2.19,3.48]$} & {$[5.11,6.65]$} & {$[5.83,7.09]$} & {$[5.94,7.30]$} & {$[0.76,2.52]$} & {$[4.61,6.35]$} \\
\hline $\mathrm{C}_{24}$ & {$[2.17,3.26]$} & {$[5.30,6.55]$} & {$[0.91,2.51]$} & {$[6.29,7.60]$} & {$[2.12,3.21]$} & {$[3.49,5.00]$} \\
\hline $\mathrm{C}_{25}$ & {$[6.18,7.65]$} & {$[5.23,6.30]$} & {$[2.71,4.44]$} & {$[6.28,7.68]$} & {$[5.21,6.82]$} & {$[4.70,5.96]$} \\
\hline $\mathrm{C}_{26}$ & {$[6.38,7.40]$} & {$[4.24,6.24]$} & {$[4.85,6.16]$} & {$[5.66,7.14]$} & {$[4.78,6.54]$} & {$[4.10,5.23]$} \\
\hline $\mathrm{C}_{27}$ & {$[6.46,7.93]$} & {$[5.95,7.24]$} & {$[3.86,5.38]$} & {$[6.35,8.02]$} & {$[2.65,4.37]$} & {$[3.71,5.40]$} \\
\hline $\mathrm{C}_{28}$ & {$[4.54,5.85]$} & {$[5.23,6.51]$} & {$[5.09,6.20]$} & {$[6.34,8.31]$} & {$[2.57,3.89]$} & {$[5.22,6.33]$} \\
\hline $\mathrm{C}_{31}$ & {$[3.61,4.84]$} & {$[5.14,6.74]$} & {$[0.87,2.65]$} & {$[6.06,7.69]$} & {$[1.13,2.58]$} & {$[3.99,5.35]$} \\
\hline $\mathrm{C}_{32}$ & {$[6.84,7.87]$} & {$[4.47,6.25]$} & {$[2.33,4.16]$} & {$[5.68,7.13]$} & {$[1.17,2.89]$} & {$[4.41,6.05]$} \\
\hline $\mathrm{C}_{33}$ & {$[5.81,7.07]$} & {$[5.01,6.26]$} & {$[3.70,5.57]$} & {$[5.96,7.05]$} & {$[4.91,6.36]$} & {$[4.11,5.51]$} \\
\hline $\mathrm{C}_{34}$ & {$[3.95,5.29]$} & {$[4.94,6.25]$} & {$[2.36,3.41]$} & {$[6.11,7.64]$} & {$[2.25,3.90]$} & {$[4.39,6.15]$} \\
\hline $\mathrm{C}_{35}$ & {$[4.63,6.40]$} & {$[4.97,6.67]$} & {$[5.82,7.80]$} & {$[7.05,8.28]$} & {$[2.51,3.67]$} & {$[4.34,5.68]$} \\
\hline $\mathrm{C}_{36}$ & {$[4.28,5.30]$} & {$[4.54,6.38]$} & {$[0.74,2.03]$} & {$[6.38,8.33]$} & {$[3.78,5.62]$} & {$[3.93,5.71]$} \\
\hline $\mathrm{C}_{37}$ & {$[6.68,8.43]$} & {$[5.06,6.32]$} & {$[4.79,6.10]$} & {$[6.87,8.32]$} & {$[1.80,2.84]$} & {$[4.84,6.37]$} \\
\hline $\mathrm{C}_{38}$ & {$[5.49,7.44]$} & {$[4.11,6.03]$} & {$[0.17,2.08]$} & {$[5.47,7.20]$} & {$[1.07,2.73]$} & {$[4.72,6.12]$} \\
\hline $\mathrm{C}_{39}$ & {$[6.19,7.58]$} & {$[4.47,6.23]$} & {$[2.72,4.26]$} & {$[5.85,7.36]$} & {$[2.80,4.31]$} & {$[4.23,5.65]$} \\
\hline$C_{310}$ & {$[2.17,3.95]$} & {$[4.68,6.35]$} & {$[3.75,4.97]$} & {$[7.15,8.41]$} & {$[2.73,4.61]$} & {$[5.17,6.21]$} \\
\hline
\end{tabular}

In the next step of applying improved GRA, the grey relational decision matrix is normalized by using Equations (10) and (11). Then, reference alternative is determined by Equation (12) and its distance with the alternatives is calculated using Equation (12). Grey relational coefficient is obtained using Equation (14). Equation (15) is utilized to provide the grey relational degree for each alternative, which is reported in the second column of Table 8 . It should be mentioned that in Equation (15), $w_{j}$ shows the weight of $j$-th subcriterion, which is the result of applying fuzzy AHP. Finally, the grey relational degree for each alternative is whitened by using Equation (16). The whitened relational degree is reported in the third column of Table 8. The last column of Table 8 shows the priority of construction projects. As the results show, Negin Chaharbagh recreational and commercial complex $\left(\mathrm{P}_{4}\right)$ is the best project based on sustainable development dimensions. The grey relational degree for this project is [0.190, 0.279], and its whitened grey relational degree is equal to 0.234 , which is the largest value among whitened degree values. After that, Anooshirvan recreational, commercial, and official complex $\left(\mathrm{P}_{2}\right)$ and Fadak center recreational, tourism, and commercial complex $\left(\mathrm{P}_{1}\right)$ have the largest values of the whitened relational degree. Therefore, they have the second and third ranks based on sustainable development concept among six construction projects, respectively.

Table 8. The results of improved grey relational analysis for assessing construction projects.

\begin{tabular}{cccc}
\hline Construction Project & Grey Relational Coefficient $\left(\otimes \Gamma_{\boldsymbol{i}}\right)$ & Whitened Grey Relational Degree $\left(\Gamma_{\boldsymbol{i}}\right)$ & Rank \\
\hline $\mathrm{P}_{1}$ & {$[0.160,0.220]$} & 0.190 & 3 \\
$\mathrm{P}_{2}$ & {$[0.170,0.237]$} & 0.203 & 2 \\
$\mathrm{P}_{3}$ & {$[0.150,0.199]$} & 0.174 & 5 \\
$\mathrm{P}_{4}$ & {$[0.190,0.279]$} & 0.234 & 1 \\
$\mathrm{P}_{5}$ & {$[0.142,0.187]$} & 0.165 & 6 \\
$\mathrm{P}_{6}$ & {$[0.158,0.214]$} & 0.186 & 4 \\
\hline
\end{tabular}




\subsection{Summary of Findings}

In this paper, 26 indicators of sustainability in the economic, environmental, and social fields were utilized to assess six construction projects in Isfahan, Iran. The importance and weight of each aspect of sustainability criteria was calculated using the fuzzy AHP method. The weight of economic, social, and environmental criteria has been equal to $0.330,0.321$, and 0.349 , respectively. These results indicate that environmental criteria are more important than the economic and social criteria. However, the results are very close to each other, which indicate that the importance of all three aspects of sustainability is almost equal to each other. In summary, there are two methods for demonstrating the effects and relations among aspects of sustainability. In the first method, as shown in Figure 3, there is an overlap among the aspects of sustainability. In the second method, depicted in Figure 4, the economic dimension is located within the social dimension. The social dimension is also embedded in the environmental dimension. Figure 4 focuses on the central role of environment that plays in human society, and in turn, in the economy.

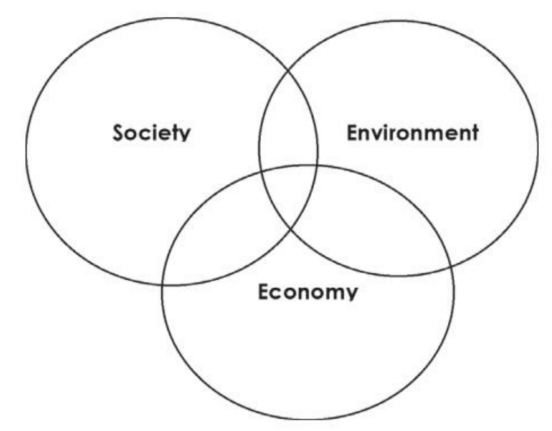

Figure 3. Overlapping aspects of sustainable development.

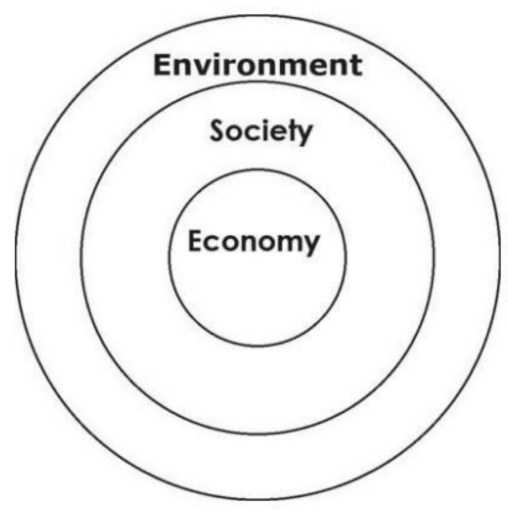

Figure 4. Concentric circles visualization of sustainable development.

According to the weight of subcriteria, "adherence to environmental policies" $\left(\mathrm{C}_{310}\right)$, "having profits for the society" $\left(C_{14}\right)$, and "paying attention to society and market needs" $\left(C_{13}\right)$ are the most important sustainability subcriteria. Furthermore, "having profits for the society" $\left(\mathrm{C}_{14}\right)$, "Increasing social justice" $\left(C_{28}\right)$, and "adherence to environmental policies" $\left(C_{310}\right)$ with the weight scores of 0.057 , 0.053, and 0.058, are the most important criteria in the economic, social, and environmental aspects, respectively. The results of improved GRA are applied to prioritize the construction projects based on their whitened grey relational degrees. According to these results, the priority of construction projects is as: $P_{4}>P_{2}>P_{1}>P_{6}>P_{3}>P_{5}$. 


\section{Conclusions}

Due to the importance of sustainable development in construction, the study assesses construction projects based on sustainable development indices using fuzzy AHP and improved GRA. For doing so, 8 subcriteria in the economical dimension, 8 subcriteria in the social dimension, and 10 subcriteria in the environmental dimension were extracted from literature review, and customized by experts' opinions. After that, two questionnaires related to fuzzy AHP and improved GRA were designed in order to collect data in the form of linguistic terms. After distributing questionnaires and collecting data, linguistic terms were converted to the corresponding fuzzy and grey ratings. Fuzzy AHP was used for determining the importance of criteria of sustainable development and their subcriteria. The results of applying fuzzy AHP shows that among sustainable development dimensions, environmental criteria are more important than other dimensions. Also, among sustainable development subcriteria, "adherence to environmental policies", "having profits for the society", and "paying attention to society and market needs" are the most important. Finally, considering the weights acquired through fuzzy AHP method, improved GRA was used for assessing and prioritizing six construction projects in Isfahan based on sustainable development indices. The results of employing this method revealed that the best construction project regarding the sustainable development indices is Negin ChaharBagh recreational and commercial complex.

Author Contributions: The individual contribution and responsibilities of the authors were as follows: Seyed Morteza Hatefi and Jolanta Tamošaitiené-Developing a new quantitative; Seyed Morteza Hatefi and Jolanta Tamošaitienè-Providing an appropriate method; Seyed Morteza Hatefi-Implementation of the proposed model in a real case study; Seyed Morteza Hatefi-Designed the research, methodology, performed the development of the paper; Seyed Morteza Hatefi-Collected and analyzed the data and the obtained results; Jolanta Tamošaitienè-Provided extensive advice throughout the study; Jolanta Tamošaitienè-Regarding the research design, revised the manuscript; Seyed Morteza Hatefi and Jolanta Tamošaitienė-Methodology, findings. All the authors have read and approved the final manuscript.

Conflicts of Interest: The authors declare no conflict of interest.

\section{References}

1. Tabassi, A.A.; Roufechaei, K.M.; Ramli, M.; Bakar, A.H.A.; Ismail, R.; Pakir, A.H.K. Leadership competences of sustainable construction project managers. J. Clean. Prod. 2016, 124, 339-349. [CrossRef]

2. Hatefi, S.M. Strategic planning of urban transportation system based on sustainable development dimensions using an integrated SWOT and fuzzy COPRAS approach. Glob. J. Environ. Sci. Manag. 2018, 4, 99-112.

3. Mohammadizadeh, M.J.; Karbassi, A.R.; Nabi Bidhendi, G.R.; Abbaspour, M. Integrated environmental management model of air pollution control by hybrid model of DPSIR and FAHP. Glob. J. Environ. Sci. Manag. 2016, 2, 381-388.

4. Haghshenas, H.; Vaziri, M.; Gholamialam, A. Evaluation of sustainable policy in urban transportation using system dynamics and world cities data: A case study in Isfahan. Cities 2015, 45, 104-115. [CrossRef]

5. Pazouki, M.; Jozi, S.A.; Ziari, Y.A. Strategic management in urban environment using SWOT and QSPM model. Glob. J. Environ. Sci. Manag. 2017, 3, 207-216.

6. Wang, N.; Adeli, H. Sustainable building design. J. Civ. Eng. Manag. 2014, 20, 1-10. [CrossRef]

7. Alwaer, H.; Clements-Croome, D.J. Key performance indicators (KPIs) and priority setting in using the multi-attribute approach for assessing sustainable intelligent buildings. Build. Environ. 2010, 45, 799-807. [CrossRef]

8. Alkaff, S.A.; Sim, S.C.; Ervina Efzan, M.N. A review of underground building towards thermal energy efficiency and sustainable development. Renew. Sustain. Energy Rev. 2016, 60, 692-713. [CrossRef]

9. Mousavi, S.M.; Gitinavard, H.; Vahdani, B. Evaluating construction projects by a new group decision-making model based on intuitionistic fuzzy logic concepts. Int. J. Eng. 2015, 28, 1312-1319.

10. Vahdani, B.; Mousavi, S.M.; Hashemi, H.; Mousakhani, M.; Ebrahimnejad, S. A new hybrid model based on least squares support vector machine for project selection problem in construction industry. Arab. J. Sci. Eng. 2014, 39, 4301-4314. [CrossRef] 
11. Zavadskas, E.K.; Turskis, Z.; Tamošaitiene, J. Risk assessment of construction projects. J. Civ. Eng. Manag. 2010, 16, 33-46. [CrossRef]

12. Chatterjee, K.; Zavadskas, E.K.; Tamošaitienè, J.; Adhikary, K.; Kar, S. A hybrid MCDM technique for risk management in construction projects. Symmetry 2018, 10, 46. [CrossRef]

13. Taylan, O.; Bafail, A.O.; Abdulaal, R.M.S.; Kabli, M.R. Construction projects selection and risk assessment by fuzzy AHP and fuzzy TOPSIS methodologies. Appl. Soft Comput. 2014, 17, 105-116. [CrossRef]

14. Islam, M.S.; Nepal, M.P.; Skitmore, M.; Attarzadeh, M. Current research trends and application areas of fuzzy and hybrid methods to the risk assessment of construction projects. Adv. Eng. Inform. 2017, 33, 112-131. [CrossRef]

15. Yazdani-Chamzini, A. Proposing a new methodology based on fuzzy logic for tunnelling risk assessment. J. Civ. Eng. Manag. 2014, 20, 82-94. [CrossRef]

16. Iqbal, S.; Choudhry, R.; Holschemacher, K.; Ali, A.; Tamošaitienė, J. Risk management in construction projects. Technol. Econ. Dev. Econ. 2015, 21, 65-78. [CrossRef]

17. Hashemi, S.H.; Karimi, A.; Tavana, M. An integrated green supplier selection approach with analytic network process and improved Grey relational analysis. Int. J. Prod. Econ. 2015, 159, 178-191. [CrossRef]

18. Saaty, T. Analytic Hierarchy Process: Planning, Priority Setting; RWS: Chalfont St Peter, UK, 1980.

19. Saaty, T. Theory and Applications of the Analytic Network Process: Decision Making With Benefits, Opportunities, Costs, and Risks; RWS Publications: Chalfont St Peter, UK, 2005.

20. Chang, D.Y. Applications of the extent analysis method on fuzzy AHP. Eur. J. Oper. Res. 1996, 95, 649-655. [CrossRef]

21. Kahraman, C. Fuzzy Multi-Criteria Decision Making: Theory and Applications with Recent Developments. Available online: http:/ / www.springer.com/gp/book/9780387768120 (accessed on 20 March 2018).

22. Deng, J.L. Control problems of grey system. Syst. Control Lett. 1982, 1, 288-294.

23. Deng, J.L. Introduction to Grey system theory. J. Grey Syst. 1988, 1, 1-24.

24. Deng, J.L. Properties of relational space for grey systems. In Essential Topics on Grey System-Theory and Applications; China Ocean Press: Beijing, China, 1988; pp. 1-13.

25. Zavadskas, E.K.; Kaklauskas, A.; Turskis, Z.; Tamošaitienè, J. Selection of the effective dwelling house walls by applying attributes values determined at intervals. J. Civ. Eng. Manag. 2008, 14, 85-93. [CrossRef]

26. Zavadskas, E.K.; Kaklauskas, A.; Turskis, Z.; Tamošaitienè, J. Multi-attribute decision-making model by applying grey numbers. Informatica 2009, 20, 305-320. 